\title{
Review and simulation of passive seismic tomography in block cave mining
}

\author{
S Ghaychi Afrouz Virginia Polytechnic Institute and State University, USA \\ EC Westman Virginia Polytechnic Institute and State University, USA
}

\begin{abstract}
Seismic tomography methods are progressing in crustal seismology and at the smaller mining scale to recognise highly stressed or fracture-prone areas. Velocity variations measured by seismic tomography represent stress concentrations in the rock mass. Changes in these stress conditions are of interest in mining as they are linked to the instability of the underground openings. Rock fracturing generates seismic waves, which propagate with different velocities through portions of the rock mass that have different moduli.

Both known and unknown seismic sources in mining environments generate active and passive tomography data, respectively. Active tomography utilises a known source time and location, while passive seismic tomography uses the mining-induced seismic events, for which the source time and location can only be estimated. Mining-induced seismic events generally have relatively low magnitudes, typically lower than $M_{L}=3$.

The pattern of stress redistribution varies based on different mining methods at different depths. In this study, development of seismic tomography in the mining industry is traced through a review of background theory and recent applications. Additionally, a block caving simulation is presented, including the imaging of cave development, load distribution, and abutment zones. A simple elastic numerical model is used to model stress distribution surrounding a hypothetical block cave. Velocities are assigned to portions of the model corresponding to the stress level. With this velocity model, synthetic travel times are modelled. The synthetic travel times are then used as input to the tomography code. The velocity distribution, which is then generated through the tomography calculations, is compared to the initial, modelled velocity distribution providing a means for validating the quality of the results of the tomography approach for this application.
\end{abstract}

Keywords: seismic tomography, block caving, stress redistribution, mining-induced seismicity

\section{Introduction}

One of the most significant challenges in block cave mining is the unknown condition of abutment loading in the rock mass. This has a material impact upon safety and production. Movement along structures and rock deformations affect abutment stress distribution conditions (Han et al. 2014). Therefore, it is relevant to track rock mass deformation in the early stages of potential failures in order to mitigate ground movement hazards, which benefits both safety and production. For this purpose, the high-stress areas have to be identified and destressed. Direct measurement of underground stress in abutment rock is not easily achieved, particularly at full scale, in mining (Hoek et al. 2000). Petr et al. (2016) applied strain gauge probes as a reliable tool to measure in situ stress of rock mass. The applicability of such methods for the discrete measurement of stress changes in the rock mass has limitations with respect to the ability to process the information in real time, as well as the number of instruments that can practically be installed in a given region. External factors, such as regular drilling and blasting, might apply excessive energy to unknown underground discontinuities, which may not have been interpreted and mapped as a result of exploration or pilot drilling.

Passive seismic tomography allows for the indirect measurement of underground stress in abutments. This proactive approach to ground control hinges upon indirectly determining the seismic velocity changes in the rock mass, which is directly correlated to the stress. Stress redistribution can be visualised by applying seismic velocity tomography on a temporal scale. 
This study proposes that the zones identified with high velocity in the abutment in situ rock mass and the fractured rock above the caved area in a block cave mine represent the areas with the most concentration of the induced stress. For this purpose, the seismic velocity tomograms are compared with the numerical analysis of stress.

\subsection{Computed tomography}

Computed or computerised tomography (CT) uses computer-processed calculations to model an object via cross-sectional images from different angles which are generated by any wave which can penetrate the object and be measured (Herman 2009). The penetrating wave can be an X-ray, an electrical wave, an acoustic wave or even a seismic wave. For example, CT scan machines used in medical imaging use X-rays to penetrate the human body. The inside of the solid body, which the wave passes through, can be modelled using tomography. In this method, the wave velocity through a homogeneous material is considered constant. Knowing the travel time of the wave can allow us to determine the origin of the wave. Wave attenuation for specific materials can also be characterised. Therefore, any changes in the wave travel time are due to changes in structures or material inside the body. However, the solution is not unique spatially due to a limited number of received waves used in the chosen tomography method. Any known source and velocity of the wave through the body are essentially valid for calculations.

Seismic velocity refers to the velocity of the body waves in the rock mass. Body waves include P-waves and $\mathrm{S}$-waves, which propagate inside the solid rock in compression and shear respectively. The P-waves travel faster and are received first after the occurrence of a seismic event. Seismic tomography is based on the travel time of these waves inside the rock mass. The travel time of a seismic wave through the rock mass gives an average of the wave speed (also known as the apparent velocity) along the wave's ray path, which is the path that seismic wave travels from the source to the receiver.

In this method, a homogeneous initial model of constant P-wave velocity is considered to determine the dominant velocity of the rock mass as the medium (Westman 2004). The source of P-wave propagation, which is termed the seismic event, can be a micro-scale crack in the rock mass with the local magnitude of less than 3 . The origin location and time of the seismic events are considered as the source parameters. Therefore, the source and medium parameters will be determined based on the best-fitted P-wave arrival time in the least squares solution.

\subsection{Seismic tomography}

The most common seismic tomography methods are transmission tomography, diffraction tomography, attenuation tomography, travel time tomography and double-difference (DD) tomography. These methods are used according to whether time travel data or waveform data are utilised (Kerr 2011).

Transmission tomography is based on the inversion of travel times of $\mathrm{P}$-waves. Diffraction tomography is the inversion of the reflected wave, which is scattered by the targeted object, in order to remodel the cause of scattering. Diffraction tomography can have the same resolution as transmission tomography with less coverage of sources and receivers (Peterson et al. 1989).

Attenuation tomography is based on the seismic amplitude and was developed for X-ray application in the medical field. It requires the waveform data in addition to the simple arrival time (Bauer et al. 2005). In seismic tomography, this method is less practical as it is highly affected by numerous unmeasurable properties of rock, such as the viscosity of interior layers (Watanabe \& Sassa 1996).

Time travel tomography has the most application in seismic velocity modelling (Farzampour \& Kamali-Asl 2015; Fehler \& Rutledge 1995). In this method the area of interest is divided into blocks. The best prediction of the velocity of each block is calculated based on ray path shortest travel time and damped least squares solutions. The residual of the predicted and observed travel times should be smaller than a defined error to stop the iteration of the process (Schuster 1998; Watanabe \& Sassa 1996). This method can be applied in 
both passive and active tomography. Different inversions of this method might apply hyperbolic or parabolic regressions based on its specific application (Fehler \& Rutledge 1995).

To calculate the travel time of waves, the quantitative concept of slowness is defined. Slowness is the inverse of the velocity of the wave and is the result of the different layers of the earth. As in Equation 1, the time travel is the integral of each block's slowness (1/velocity) along the ray path (Stein \& Wysession 2009).

$$
S(s, r)=\int_{s}^{r} \frac{1}{v(x)} d x
$$

where:

$\mathrm{S}=$ the slowness based on source ( $\mathrm{s}$ ) and receiver $(\mathrm{r})$.

$v \quad=$ the velocity of each block.

$\mathrm{x}=$ the block number.

Double-difference tomography is a relatively new variation of time travel tomography. This mathematical method was first introduced by Zhang and Thurber (2003) for near-source seismicity and was developed to be applied in hard rock underground mining by several studies, such as Kerr (2011) and Ma (2014).

\subsection{Passive seismic tomography algorithm}

In passive seismic tomography, based on the travel time, the inversion of the velocities of received waves is applied to estimate the velocity of different nodes in the rock mass. Several iterations are required to determine the most accurate estimation of the travel times. The rock mass volume is divided into smaller volumes named voxels (Brzostowski \& McMechan 1991). Each received seismic wave passing through different voxels is known as a ray (Molka 2017).

The tomography algorithm is based on the linear equation of $A x=b$ in which $b$ is the travel time residual and $\mathrm{x}$ is its received image or slowness perturbation in travel time tomography. $\mathrm{A}$ is the forward projection matrix including the distance travelled by each ray (Rawlinson et al. 2014). The travel time residual $b$ is the time difference between observation and measurement.

There are several methods to solve this equation for the velocity of each voxel, such as Gauss-Newton, algebraic reconstruction technique (ART), partially discrete iterative reconstruction technique (PDART), and simultaneous iterative reconstruction technique (SIRT) (Molka 2017).

The SIRT algorithm suggests the tomography solution with the inverse of the summation of rows and columns of the matrix $A$, which represents the projection source characteristics. $A^{\top}$ is the transposed matrix which back-projects the image and defines which voxels are exposed to a single ray as shown in Equation 2 (Roelandts 2014):

$$
x(t+1)=x(t)+C A^{\top} R(b-A x(t))
$$

where $\mathrm{C}$ and $\mathrm{R}$ are diagonal matrixes of inverse summations as $c_{j j}=1 / \sum_{i} a_{i j}$ and $r_{j j}=1 / \sum_{j} a_{i j}$, and $\mathrm{t}$ is the iteration number. The iterations start where $x^{(0)}$ is equal to zero. The optimum number of iterations can be defined based on the elbow of the time residual and the number of iterations graph.

\subsection{Passive seismic tomography application in mining}

Early studies of microseismicity in the geotechnical field go back to 1939 for hard rock mines. It gradually found its way into coal and salt mining during the 1950s (Reginald Hardy 2003). Since 1993, transducers were mounted in underground and then surface mining to determine the failure and rockburst hazards (Drnevich \& Gray 1981). Since the 1980 s, seismic monitoring systems have been used in underground mining with different mining methods such as cut-and-fill, block caving and sublevel caving to control rockburst (Trifu \& Sourineni 2009). Seismic attenuation tomography was introduced as a tool for in situ rock mass characteristics in 1996 (Watanabe \& Sassa 1996), and acoustic transmission tomography was used to map the underground rock walls in an underground power plant (Song et al. 1998). Seismic monitoring also has 
been used for environmental assessments, ore deposits, locating fractures in rock formations and determining body wave velocities and stress in the rock samples (Xu et al. 2000).

Several underground hard rock mines, such as block cave mines (Westman et al. 2012) and cut-and-fill mines (Ma 2014), have used the microseismic system to record the seismicity of the mine and conduct passive seismic tomography examining stress redistribution associated with major seismic events. Rock performance analysis, however, is not very straightforward using the recorded seismicity as there are several considerations in the system installation. The area subjected to passive tomography should have a sufficient number of sensors so that there is thorough ray path coverage for each voxel (Westman 2004). The orientation of the rays is also important to reconstruct a high-resolution velocity model. The smearing of the tomogram can also influence the accuracy of the velocity model when the majority of large events are close to each other and at some distance away from the sensors (Molka 2017).

Moreover, the background noise should be less than the incoming P-wave amplitude. Therefore, the sensors are recommended to be mounted not very close to the operation level. Additionally, sensor locations have to be stable and not damaged by blasting or other mining activities.

\section{$2 \quad$ Methods and procedure}

In this study, a hypothetical block cave mine is considered in a homogeneous rock mass with no tensile strength and cohesion of $5 \mathrm{MPa}$. The horizontal stress of the model is considered zero. A section of the mine including nine drawpoints is designed with an overburden depth of $730 \mathrm{~m}$. Figure 1 shows the dimensions of this section. The caved zone above this section has a maximum height of $325 \mathrm{~m}$.

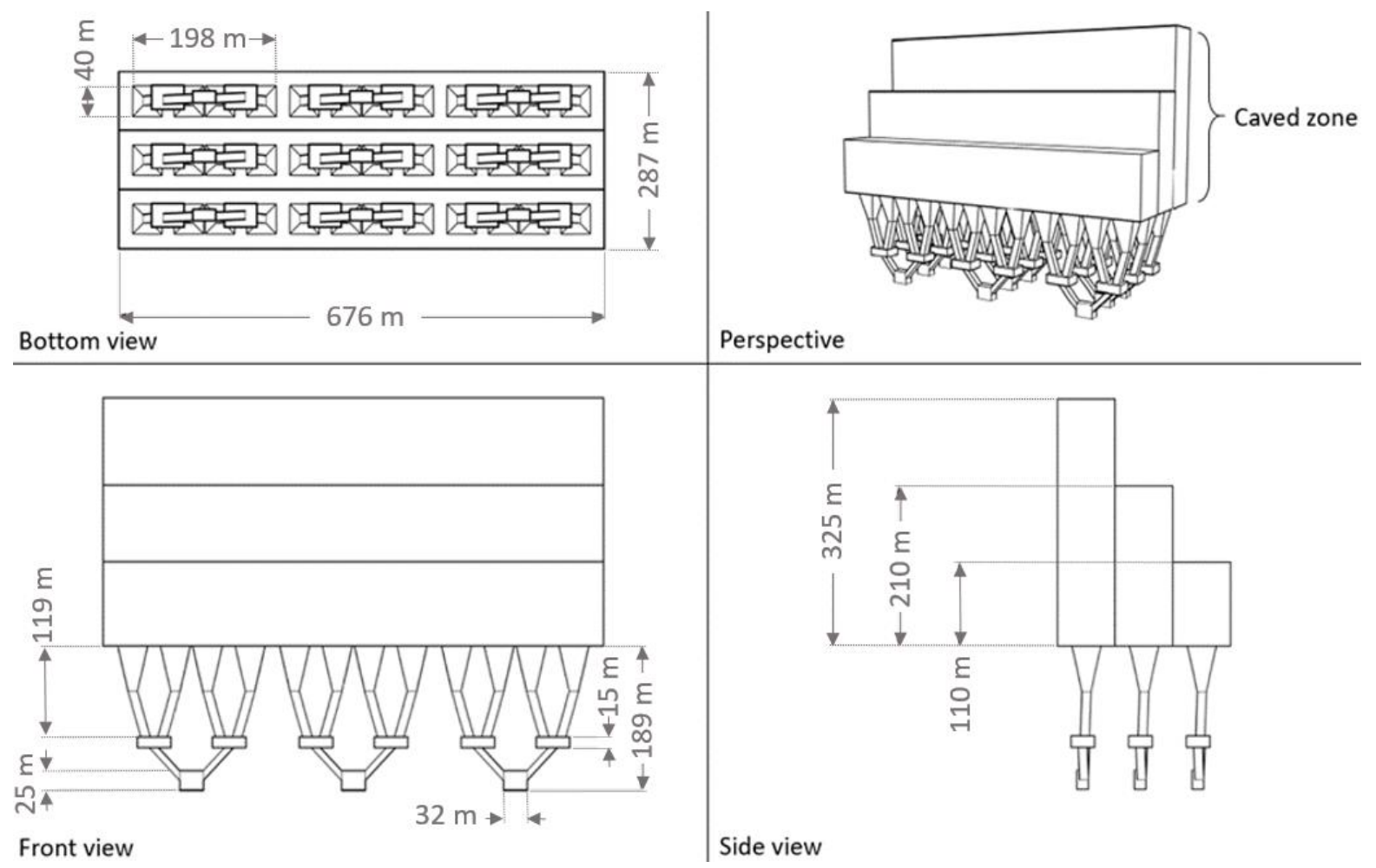

Figure 1 Dimensions of the designed section with nine drawpoints 
This section is simulated by the linear elastic boundary elements method to model the induced stress. The induced stress at each node is considered as the cumulation of the three principal stresses. The average stress of the model is calculated, and based on its variations, the velocity model is generated. The caved zone is considered as the void in this model. High-stress zones are the areas with stress greater than the average stress. A total of 430 seismic events were generated in these high-stress areas randomly. Moreover, 32 seismic receivers were placed in the rock mass around the caved zone. Figure 2 shows the location of these sensors around the mining section.

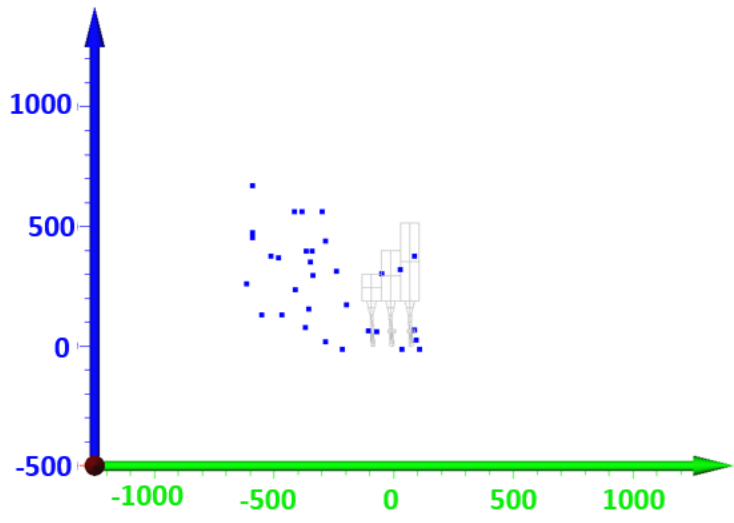

(a)

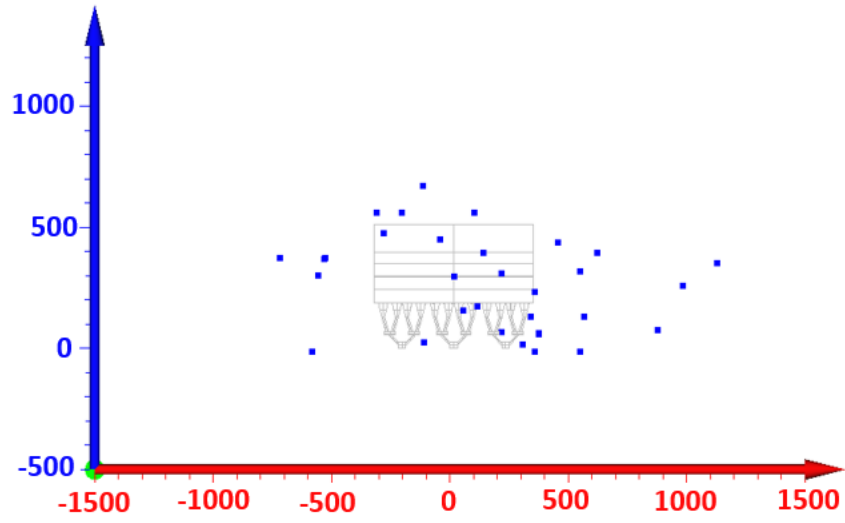

(b)

Figure 2 Sensor locations. (a) Side view; and, (b) Front view

In order to determine the effect that a varying number of ray paths has on the calculated results, three different datasets are analysed. The three datasets had 1,000, 5,000 and 20,000 synthetic ray paths. The expectation is that better images would be calculated with more ray paths. Figure 3 illustrates the event associated with these different datasets. As shown, ray path results of 20,000 (Figure 3(c)) involve more events. The fast marching method was used to simulate ray paths that refract toward high-velocity zones and around low-velocity zones. Based on the calculated travel times, the seismic velocity of the rock mass is measured through the SIRT algorithm and high-velocity and low-velocity zones are generated.

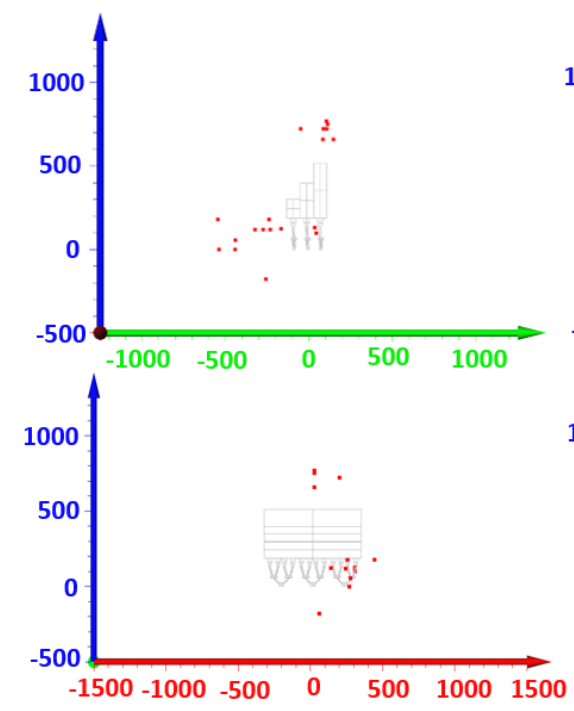

(a)

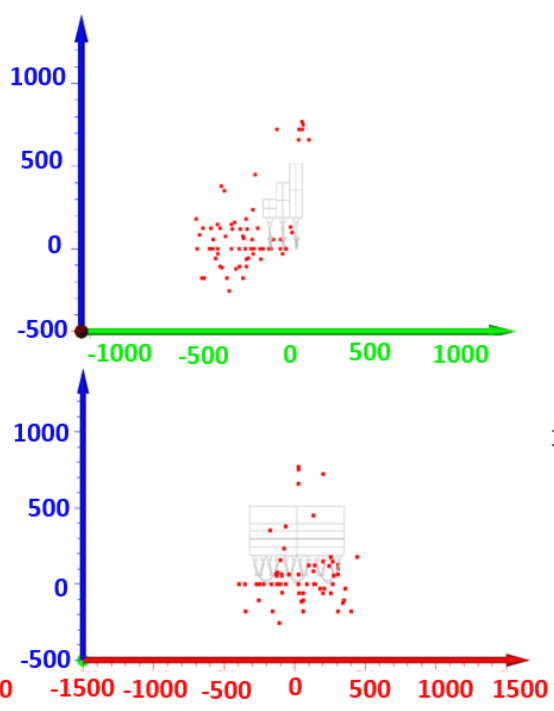

(b)

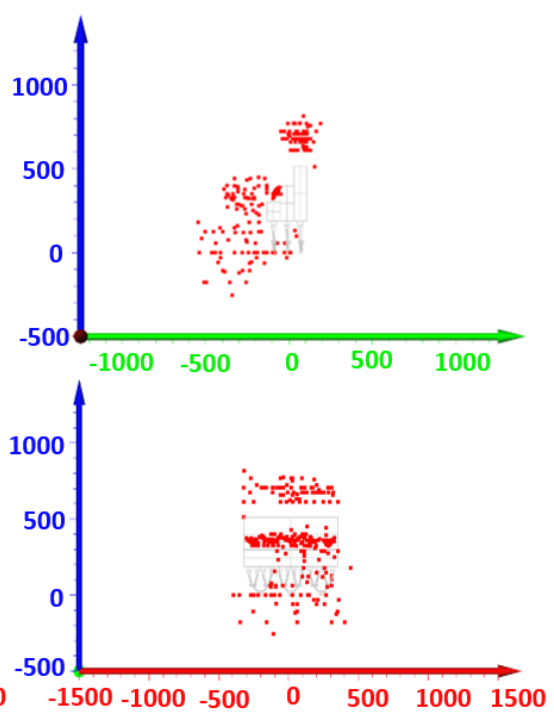

(c)

Figure 3 Event locations for (a) 1,000 ray path results; (b) 5,000 ray path results; and, (c) 20,000 ray path results 


\section{Results and discussion}

The numerical model of the induced stress for our block cave section shows high-stress areas above the cave zone and in the abutment zones. As the result of this numerical analysis, the average stress of this section is $90 \mathrm{MPa}$ with a standard deviation of 5.6 , which is $6 \%$ of the average stress. High-stress zones are areas with an isostress level of equal to or more than $93 \mathrm{MPa}$ (Figure 4). The average velocity is considered as $6,000 \mathrm{~m} / \mathrm{s}$ to form the velocity model with a standard deviation of $6 \%$ of the average velocity. Therefore, the first quartile of the velocity distribution is $5,975 \mathrm{~m} / \mathrm{s}$.

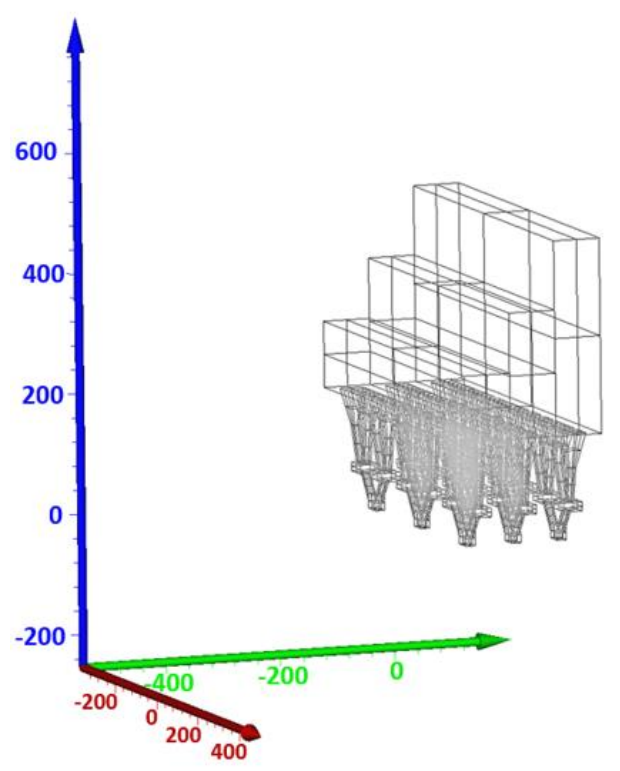

(a)

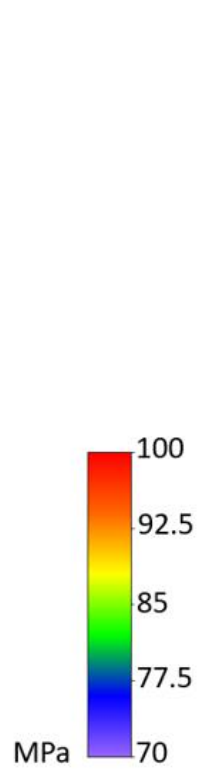

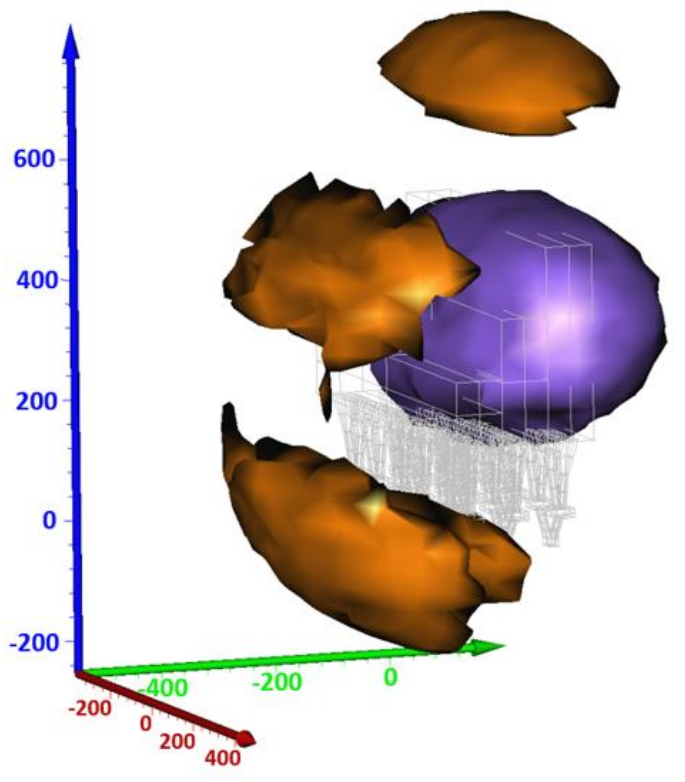

(b)

Figure 4 (a) Isometric view of modelled block cave; and, (b) Isometric view of modelled stresses around block cave. Purple is $70 \mathrm{MPa}$ isostress level, and yellow is $93 \mathrm{MPa}$ isostress level

The stress distribution at a vertical cross-section passing through the midpoint of the block cave is numerically modelled and shown in Figure 5(a). The modelled stress distribution is compared with the simulated velocities at the same cross-section (Figure $5(b)$ ). Total induced stress is shown in units of megapascals, and velocities are shown in units of metres per second.
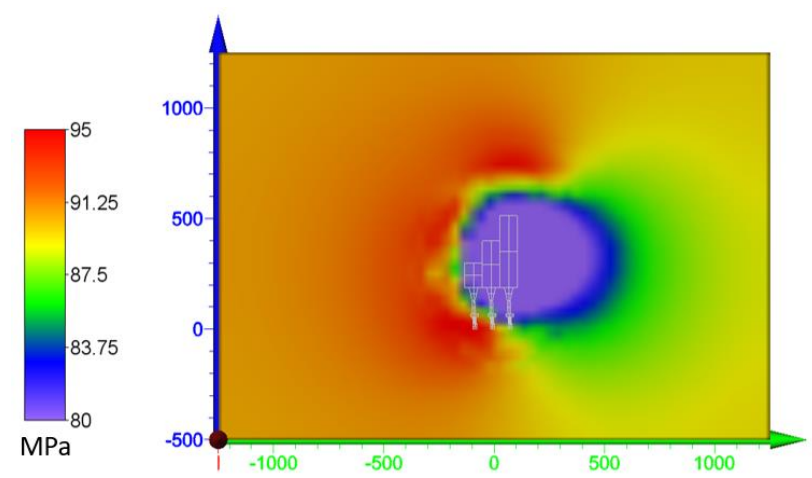

(a)
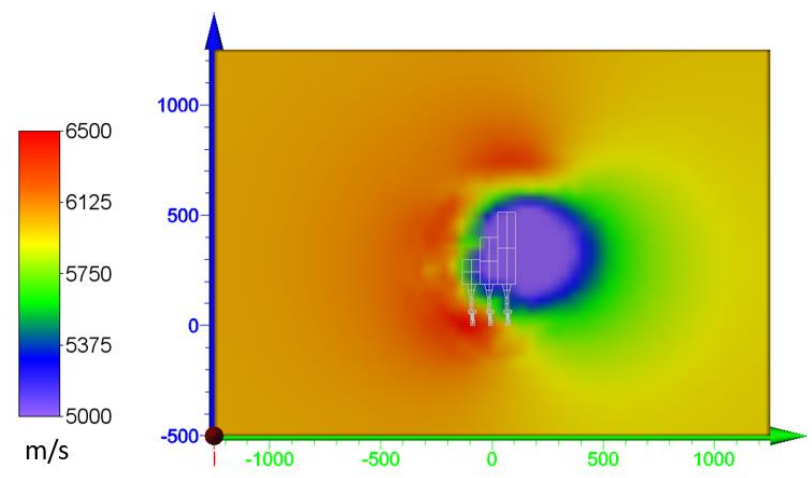

(b)

Figure 5 (a) Cross-sectional view of modelled stresses around the block cave at the midpoint; and, (b) Cross-sectional view of simulated velocities around the block cave, based on modelled stresses. Cross-section taken at the midpoint of the block cave 
Results of the tomography calculations show a velocity distribution that is similar to the modelled stress. The low-velocity cave is seen in each of the three results. Figure 6 demonstrates the effect of the number of ray paths in calculated velocity. As expected, the results using the most ray paths (Figure 6(c)) most closely agree with the expected results. On the other hand, the results using the fewest ray paths (Figure 6(a)) are somewhat smeared due to the lack of ray paths. Additionally, with fewer ray paths, the low-velocity zone is not imaged as accurately, as there are fewer ray paths associated with it.

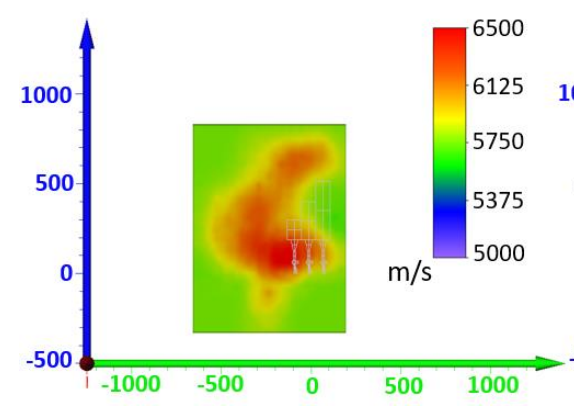

(a)

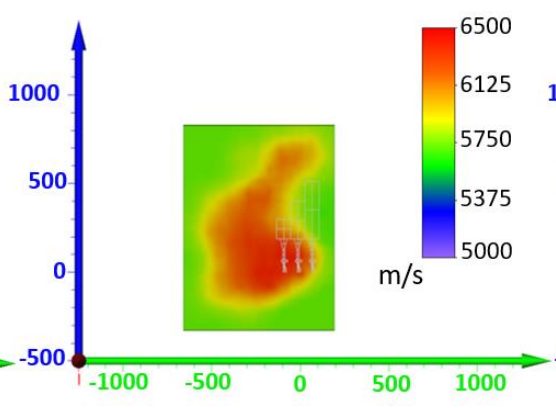

(b)

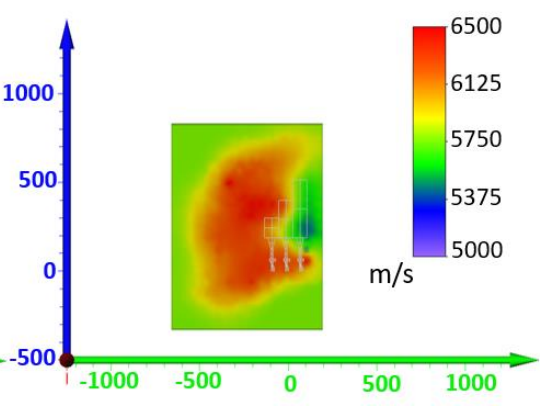

(c)

Figure 6 Cross-sectional view of calculated velocities around the block cave for (a) 1,000 ray path results; (b) 5,000 ray path results; and, (c) 20,000 ray path results. Cross-section taken at the midpoint of the block cave. Velocities shown in units of metres per second

\section{Conclusion}

Passive seismic tomography enables the indirect measurement of induced stresses in the rock mass. In the context of a block cave mine, this information may assist with operational controls to safely extract the ore. The technique can assist mine operators to identify zones with high seismic velocity in the cave abutment, as well as the fractured rock above the caved area. The high seismic velocity zones in the mine represent the areas with the highest concentration of induced stress. This study investigates seismic tomography as a remote tool to image the interior of a rock mass, which can measure seismic velocity changes in the rock mass as representative of the induced stress. As a result, high-stress zones in a numerical model of a block cave mine are in agreement with the high-velocity zones measured through the synthetic ray paths. Based on the results of this study, the seismic tomography using SIRT algorithm has a high potential to monitor induced stress distribution in block cave mines.

\section{Acknowledgement}

We thank our colleagues from the Mining and Mineral Department of Virginia Tech who provided convenience of access to licenses of software and adequate data.

\section{References}

Bauer, K, Haberland, C, Pratt, R, Hou, F, Medioli, B \& Weber, M 2005, 'Ray-based cross-well tomography for P-wave velocity, anisotropy, and attenuation structure around the JAPEX/JNOC/GSC et al. Mallik 5L-38 gas hydrate production research well', Geologic Survey of Canada Bulletin, no. 585.

Brzostowski, M \& McMechan, G 1991, '3-D tomographic imaging of near-surface seismic velocity and attenuation', Geophysics, vol. 57, pp. 396-403.

Drnevich, VP \& Gray, RE 1981, Acoustic Emissions in Geotechnical Engineering Practice, ASTM Special Technical Publication, vol. 750, ASTM International, West Conshohocken.

Farzampour, A \& Kamali-Asl, A 2015, 'Seismic hazard assessment for two cities in eastern Iran', Earthquakes and Structures, vol. 8, no. 3, pp. 681-697, https://dx.doi.org/10.12989/eas.2015.8.3.681

Fehler, M \& Rutledge, J 1995, 'Using seismic tomography to characterize fracture systems induced by hydraulic fracturing', Proceedings of the 3rd International SEGJ/SEG International Symposium on Geotomography, Society of Exploration Geophysicists, Tulsa. 
Han, H, Higgins-Borchardt, SM, Mata, D \& Gonzales, VM 2014, 'In-situ and induced stresses in the development of unconventional resources', Proceedings of the 2014 SPE/CSUR Unconventional Resources Conference, Society of Petroleum Engineers, Richardson, https://dx.doi.org/10.2118/171627-MS

Hardy Jr, HR 2003, Acoustic Emission/Microseismic Activity: Volume 1: Principles, Techniques and Geotechnical Applications, A.A. Balkema, Rotterdam.

Herman, GT 2009, Fundamentals of Computerized Tomography: Image Reconstruction from Projection, 2nd edn, Springer, London. Hoek, E, Kaiser, PK \& Bawden, WF 2000, Support of Underground Excavations in Hard Rock, A.A. Balkema, Rotterdam.

Kerr, J 2011, Applications of Double-Difference Tomography for a Deep Hard Rock Mine, MSc thesis, Virginia Polytechnic Institute and State University, Blacksburg.

Ma, X 2014, Passive Seismic Tomography and Seismicity Hazard Analysis in Deep Underground Mines, PhD thesis, Virginia Polytechnic Institute and State University, Blacksburg.

Molka, RJ 2017, Tomographic Imaging Associated with a Mw 2.6 Fault-Slip Event in a Deep Nickel Mine, MSc thesis, Virginia Polytechnic Institute and State University, Blacksburg.

Peterson Jr., JE, Majer, EL, Tura, A \& Davey A 1989, Practical Aspects of Crosswell Tomographic Surveys, University of California, Berkeley.

Petr, W, Lubomir, S, Jan, N, Petr, K \& Tomas, K 2016, 'Determination of stress state in rock mass using strain gauge probes CCBO', Procedia Engineering, vol. 149, pp. 544-552, https://dx.doi.org/10.1016/j.proeng.2016.06.703

Rawlinson, N, Fichtner, A, Sambridge, M \& Young, MK 2014, 'Seismic tomography and the assessment of uncertainty', Advanced Geophysics, no. 55, pp. 1-76.

Roelandts, T 2014, The SIRT Algorithm, viewed 27 January 2018, https://tomroelandts.com/articles/the-sirt-algorithm

Schuster, GT 1998, Basics of Exploration Seismology and Tomography, Stanford Mathematical Geophysics Summer School Lectures, University of Utah, Salt Lake City.

Song, L, Liu, H, Chun, S, Song, Z \& Zhang, S 1998, 'Mapping an underground rock mass by anisotropic acoustical transmission tomography', Ultrasonics, vol. 36, no. 10, pp. 1009-1012.

Stein, S \& Wysession, M 2009, An Introduction to Seismology, Earthquakes, and Earth Structure, Blackwell Publishing, Malden.

Trifu, C-I \& Sourineni, FT 2009, Use of Microseismic Monitoring for Rockburst Management at Vale Inco Mines, ESG Solutions, Kingston, https://www.esgsolutions.com/sites/esgsolutions.com/files/resource/2009_-_use_of_microseismic_monitoring_ for_rockburst_management_at_vale_inco_mines.pdf

Watanabe, T \& Sassa, K 1996, 'Seismic attenuation tomography and its application to rock mass evaluation', International Journal of Rock Mechanics and Mining Sciences \& Geomechanics Abstracts, vol. 33, no. 5, pp. 467-477.

Westman, EC 2004, 'Use of tomography for inference of stress redistribution in rock', IEEE Transactions on Industry Applications, vol. 40, no. 5, pp. 1413-1417.

Westman, EC, Luxbacher, K \& Schafrik, S 2012, 'Passive seismic tomography for three-dimensional time-lapse imaging of mining-induced rock mass changes', Mining Geophysics, vol. 31, no. 3, pp. 338-345, https://dx.doi.org/10.1190/1.3694902

Xu, C, Yike, L, Hui, W \& Xing, G 2000, 'Rock mass structure analysis based on seismic velocity and attenuation images', Chinese Science Bulletin, vol. 45, no. 13, pp. 1211-1216.

Zhang, H \& Thurber, HC 2003, 'Double-difference tomography: the method and its application to the Hayward Fault, California', Bulletin of the Seismological Society of America, vol. 93, no. 5, pp. 1875-1889. 